\title{
Flight Dynamics and Sensible Heat Recovery of Granulated Blast Furnace Slag
}

\author{
Lianyong Wang ${ }^{1}$, Wenqiang Sun ${ }^{*}$, Xiaoling $\mathrm{Li}^{2}$ and Jiuju Cai ${ }^{1}$ \\ ${ }^{1}$ Department of Energy and Power Engineering, Northeastern University, Shenyang, 110819, China \\ ${ }^{2}$ Faculty of Thermal Engineering, College of Petroleum Engineering, Liaoning Shihua University, Fushun, 113001, \\ China
}

\begin{abstract}
As a valuable byproduct of iron-making process, blast furnace slag contains tremendous amount of sensible heat. Granulation of blast furnace slag is the first step for its heat recovery. Due to environmental and energy issues, dry centrifugal granulation has received a considerable amount of attention. However, the flight dynamics of blast furnace slag, which is of great importance for size design of blast furnace slag granulator and heat recovery device, has been seldom reported. A granulation experiment and a heat exchange experiment were developed in this work to study the mechanisms of both flight dynamics and sensible heat recovery of blast furnace slag. It is shown that the linear velocity of the outer edge of rotary cup is bigger than the escape velocity of slag escaping from the outer edge of rotary cup. The flight distance correlates positively with either the rotation speed or the rotary cup diameter. For a constant slag cooling capacity, a negative correlation was found between air feed ratio and slag layer height. And the heat recovery efficiency has the trend of first increase and then decline with the continuously increasing slag layer height.
\end{abstract}

Keywords: Blast furnace slag, flight dynamics, granulation, heat exchange, sensible heat recovery.

\section{INTRODUCTION}

Blast furnace slag is the byproduct of iron-making process, whose discharging temperatures range from 1400 to $1600{ }^{\circ} \mathrm{C}$, with the specific sensible heat of around $1.76 \mathrm{GJ} / \mathrm{t}$. In China, 658.9 million tons of iron were produced in 2012. And 0.35 t blast furnace slag will be produced synchronously with $1 \mathrm{t}$ iron. Then the output of blast furnace slag is about 230 million tons a year, whose sensible heat accounts for $3.17 \%$ of the total energy consumption of an integrated steel plant [1-4]. Therefore, reuse of blast furnace slag sensible heat is one of the important technologies of energy conservation in steel industry. Compared with water quenching in which lost slag heat can even be recycled from slag washing water [5], dry granulation methods could realize the efficient sensible heat recovery. And the molten slag was granulated by centrifugal granulation using a rotary cup or disk in laboratory scale [6-10]. In these experiments, molten blast furnace slag was granulated into liquid drops under the action of centrifugal force and flight resistance, and then congealed to be solid particles at $850{ }^{\circ} \mathrm{C}$. Recent studies on centrifugal granulation mainly focused on the shape, size and mass distribution of slag particles and the resource utilization of blast furnace slag [11-13]. However, the dynamics parameters, such as the velocity of molten blast furnace slag escaping from the outer edge of rotary cup (hereinafter referred to as escape velocity) and the flight distance of blast furnace slag, have not received enough

\footnotetext{
*Address correspondence to this author at the Department of Energy and Power Engineering, Northeastern University, Shenyang, 110819, China; Tel: +86-24-83672218; Fax: +86-24-83672218; E-mail: neu20031542@163.com
}

attention. They are just the key parameters for the size design of molten blast furnace slag granulation device. The object of slag granulation is to obtain the sensible heat of granulated blast furnace slag. Either packed bed or moving bed [14-17], for dry granulation method, air is the normal heat exchange medium. So the factors influencing heat recovery rate and their contribution are of great concern for the heat recovery process.

In the present work, escape velocity and flight distance of blast furnace slag under several conditions in the centrifugal granulation process were studied, which may provide reference for designing centrifugal granulation device. Then the heat recovery effect of granulated blast furnace slag and air in a moving bed were studied to get the regulation of heat recovery rate with various air flow rates and slag layer heights.

\section{FLIGHT DYNAMICS EXPERIMENTAL}

\subsection{Experimental Apparatus}

The experimental mainly consists of six parts: melting, delivering, pouring, granulating, cooling and collecting, as is shown in Fig. (1). Crucible was heated in a medium frequency coreless induction melting furnace with a power of $80 \mathrm{~kW}$ for 1.5 hours. Next, the blast furnace slag was tipped into the heated crucible; and the heating power was changed to $120 \mathrm{~kW}$. The heating process continued until blast furnace slag was melted completely with the temperature level of $1400{ }^{\circ} \mathrm{C}$, whose duration was around 2.5 hours. To reduce the temperature drop of blast furnace slag, both turnover ladle and tundish were preheated by propane for 4 hours before containing liquid molten slag. 
Then the pouring liquid slag was granulated into particles by the granulator and collector with the diameter of $2.4 \mathrm{~m}$ and height of $1.7 \mathrm{~m}$.

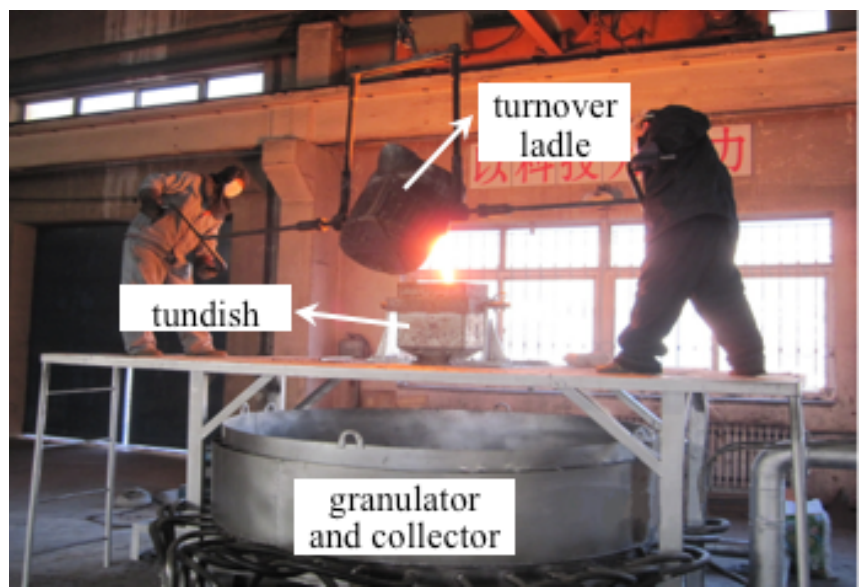

Fig. (1). Photo of experimental apparatus.

\subsection{Results and Discussions}

When liquid slag was poured from the turnover ladle, molten blast furnace slag fell from tundish to rotary cup surface with a high velocity. And the molten slag started its circular motion under the effects of gravity, centrifugal force, and frictional force. Then the molten blast furnace slag escaped from the outer edge of the rotary cup. In the flight process, molten slag was granulated into liquid drop and congealed to be spherical particles by the action of surface tension and air resistance. Finally, granulated particles were dropped into the collector and recycled after exchanging heat with air- or water-cooled wall.

It can be seen from Fig. (2) that molten slag spilled around at a certain velocity. The flight process can be reduced to a horizontal projectile motion. The flight time of blast furnace slag was determined by freely falling body motion in the vertical direction. If slag particle fell directly on the disc collector, the free fall height of blast furnace slag was the vertical distance from the rotary cup outer edge to the disc; while if slag particle hit the collector wall, the free fall height was the vertical distance from the rotary cup outer edge to the hit point. For the two situations, each free fall height can be measured. Then the flight time can be calculated by:

$t=\sqrt{2 h / g}$

where $t$ is the flight time, $h$ is the free fall height, and $g$ is acceleration of gravity.

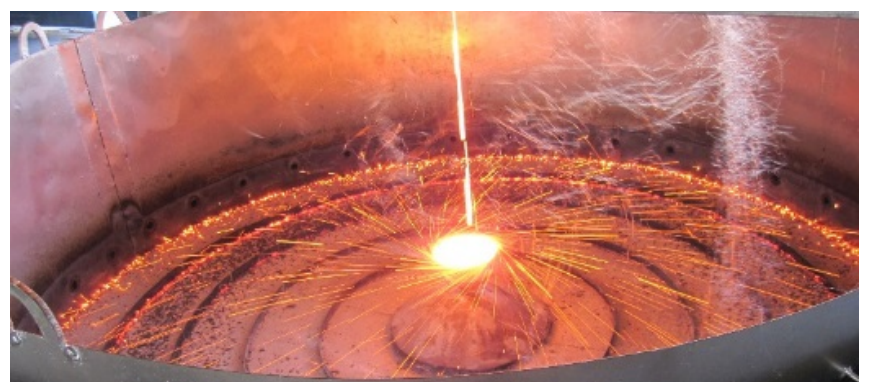

Fig. (2). Granulation process of molten blast furnace slag.
The disc collector, with rotary cup as its center, was divided into five annular regions, as shown in Fig. (3). The average distances from rotary cup outer edge to the outer edges of these five annular regions are presented as $l_{1}, l_{2}, l_{3}$, $l_{4}$, and $l_{5}$, respectively. So the escape velocity of blast furnace slag is:

$v=l / t$

where $v$ is the escape velocity.

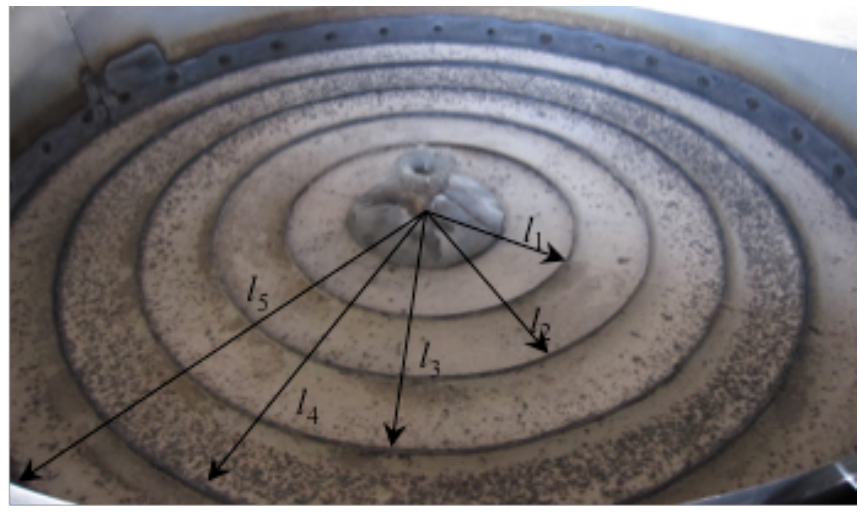

Fig. (3). Five annual regions of experimental disc collector.

Escape velocity is the key factor influencing the centrifugal granulation of molten blast furnace slag. With the slag mass flow rate of $270 \mathrm{~g} / \mathrm{s}$ and temperature of $1400^{\circ} \mathrm{C}$, the relationship between escape velocity, linear velocity of rotary cup outer edge (hereinafter referred to as linear velocity), and rotation speed $(\omega)$ was given in Fig. (4). It can be found that linear velocity is greater than escape velocity; and the difference grows bigger as the rotation speed increases.

To express the relationship between escape velocity and linear velocity, relative velocity difference is defined as:

$v^{*}=\left(v-v^{\prime}\right) / v^{\prime}$

where $v^{*}$ and $v^{\prime}$ represent the relative velocity difference and linear velocity, respectively.

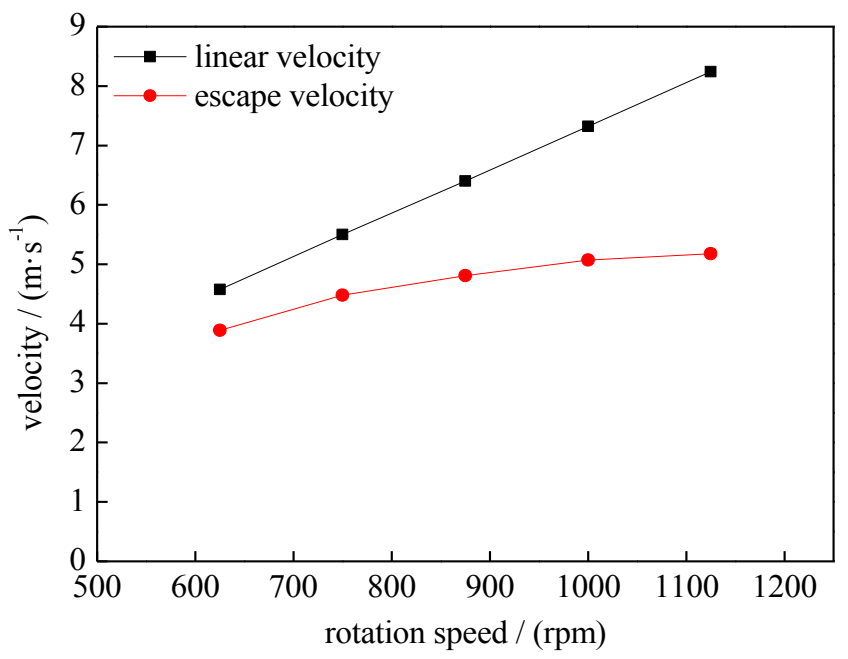

Fig. (4). Influence of rotation speed on linear and escape velocity.

From the regulations reported in Fig. (4), the relative velocity difference could be calculated as given in Table $\mathbf{1}$. As the rotation speed increases, the escape velocity gets 
slower while the relative velocity difference gets bigger. Thus, it has its limitations to increase the escape velocity by only increasing the rotation speed of rotary cup.

Table 1. Relative velocity differences at different rotation speeds.

\begin{tabular}{|c|c|c|c|c|c|}
\hline $\boldsymbol{\omega}$ (rpm) & $\mathbf{6 2 5}$ & $\mathbf{7 5 0}$ & $\mathbf{8 7 5}$ & $\mathbf{1 0 0 0}$ & $\mathbf{1 1 2 5}$ \\
\hline \hline$v^{*}$ & 0.15 & 0.18 & 0.25 & 0.31 & 0.37 \\
\hline
\end{tabular}

With the molten granulated slag mass flow rate of 270 $\mathrm{g} / \mathrm{s}$ and temperature of $1400{ }^{\circ} \mathrm{C}$, the relationship between escape velocity, and linear velocity, and rotary cup diameter (d) was given in Fig. (5).

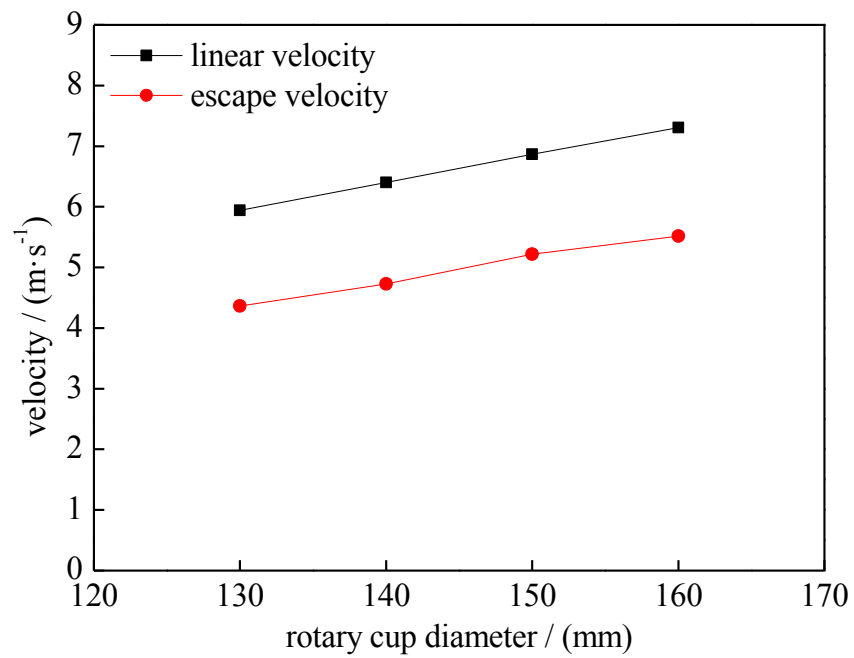

Fig. (5). Influence of rotary cup diameter on linear and escape velocity.

In the like manner, the linear velocity is greater than escape velocity. However, the difference between linear and escape velocity remains largely unchanged. The relative velocity differences are presented in Table 2 with different rotary cup diameters. It can be drawn from Table 2 that the escape velocity gets higher while the relative velocity difference gets smaller as rotation speed increases. Thus it is effective to increase the escape velocity by adjusting the diameter of rotary cup.

Table 2. Relative velocity differences at different rotary cup diameters.

\begin{tabular}{|c|c|c|c|c|}
\hline $\boldsymbol{d}(\mathbf{m m})$ & $\mathbf{1 3 0}$ & $\mathbf{1 4 0}$ & $\mathbf{1 5 0}$ & $\mathbf{1 6 0}$ \\
\hline \hline$v^{*}$ & 0.267 & 0.261 & 0.242 & 0.240 \\
\hline
\end{tabular}

Flight distance is defined as the radial distance from the center of rotary cup to the slag landing point. It is the key parameter for size design of blast furnace slag granulator, as important as the cooling effect of liquid slag drop. With the slag mass flow rate of $270 \mathrm{~g} / \mathrm{s}$ and temperature of $1400{ }^{\circ} \mathrm{C}$, the relationship between slag flight distance and rotary cup diameter was given in Fig. (6). It can be seen that the flight distance will be farther while the rotation speed and/or rotary cup diameter increases.

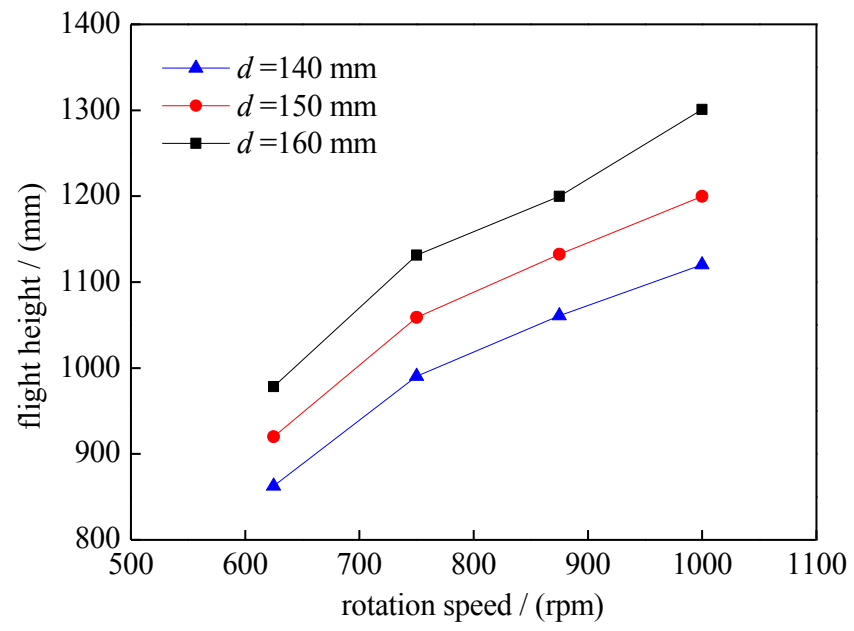

Fig. (6). Influence of rotation speed on flight distance.

\section{HEAT RECOVERY EXPERIMENTAL}

\subsection{Experimental Apparatus}

The heat recovery apparatus is shown in Fig. (7). The height and diameter of the moving bed were $1.2 \mathrm{~m}$ and 1.0 $\mathrm{m}$, respectively. The inlet temperatures of circulating air and blast furnace slag were $300 \mathrm{~K}$ and $1450 \mathrm{~K}$ respectively, and the outlet temperature of blast furnace slag was lower than $450 \mathrm{~K}$. Slag layer height directly impacts the gas-solid heat contact time, as well as gas-solid heat exchange quantity. Similarly, the flow rate of circulating air also influences the heat exchange effect. So slag layer height and the flow rate of circulating air were examined in the present work under the slag cooling capacities of $1.5,3.0,4.5$ and $6.0 \mathrm{t} / \mathrm{h}$. The initial flow rate of circulating air was $5000 \mathrm{~m}^{3} / \mathrm{h}$. And the slag layer heights were set as $0.6,0.8,1.0$ and $1.2 \mathrm{~m}$. The slag density was $1800 \mathrm{~kg} / \mathrm{m}^{3}$ and its mean specific heat capacity at constant pressure was $1050 \mathrm{~J} /(\mathrm{kg} \cdot \mathrm{K})$.

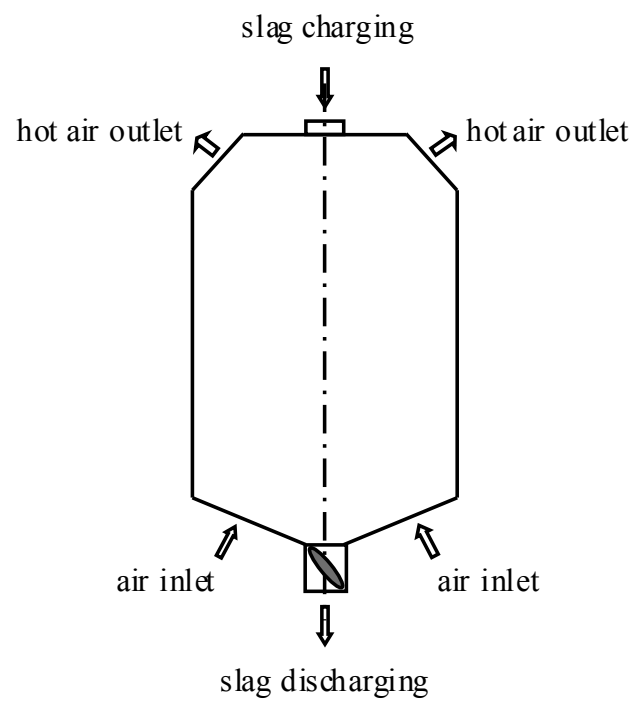

Fig. (7). Schematic diagram of moving bed.

\subsection{Results and Discussions}

Heat recovery efficiency was selected as the evaluating index of heat exchange effect and defined as: 


$$
\eta=Q_{\mathrm{a}} \rho_{\mathrm{a}} c_{\mathrm{a}}\left(T_{\mathrm{a}}-T_{0}\right) /\left[Q_{\mathrm{s}} c_{\mathrm{s}}\left(T_{\mathrm{s}}-293\right)\right] \times 100 \%
$$

where $\eta$ is the heat recovery efficiency of the moving bed; $Q_{\mathrm{a}}, \rho_{\mathrm{a}}$, and $c_{\mathrm{a}}$ are the flow rate, density and specific heat of circulating air, respectively; $Q_{\mathrm{s}}$ and $c_{\mathrm{s}}$ are the slag cooling capacity and specific heat of blast furnace slag, respectively; $T_{0}$ and $T_{\mathrm{a}}$ are the temperatures of inlet and outlet of circulating air; and $T_{\mathrm{s}}$ is the initial temperature of blast furnace slag.

At a set slag cooling capacity, the outlet temperature of slag would be reduced if the flow rate of circulating air increased, because the sensible heat of blast furnace slag was recycled by circulating air. However, if the flow rate of circulating air continued increasing, the average outlet temperature of air would be reduced. Therefore, an optimal air feed ratio, the ratio of flow rate of circulating air to slag cooling capacity, does exist.

Air feed ratio, slag outlet temperature, and air outlet temperature are listed in Tables 3-6 at different slag layer heights $(H)$. When slag layer height is $0.6 \mathrm{~m}$ as presented in Table 3, air feed ratio should be increased to reach the same heat exchange effect if the slag cooling capacity increased. The outlet temperature of circulating air remained about 900 $\mathrm{K}$. From Table 4, slag layer height increased by $0.2 \mathrm{~m}$, air feed ratio also grew as the slag cooling capacity increased; however, the air feed ratio had a trend of reduction with circulating air outlet temperature of around $920 \mathrm{~K}$. Thus, increasing slag layer height favors a smaller air feed ratio, resulting in the reduction of circulating air flow rate. It can be seen from Table $\mathbf{5}$ that the outlet temperature of circulating air increased to about $950 \mathrm{~K}$ when slag layer height was $1.0 \mathrm{~m}$. When slag layer height increased to $1.2 \mathrm{~m}$ as shown in Table 6, the falling speed and air feed ratio slowed down, and the outlet temperature of circulating air remained about $955 \mathrm{~K}$, that is increased by an insignificant amount.

Table 3. Values of $Q_{\mathrm{a}} / Q_{\mathrm{s}}, T_{\mathrm{s}}$, and $T_{\mathrm{a}}$ at $H=0.6 \mathrm{~m}$.

\begin{tabular}{|c|c|c|c|}
\hline $\boldsymbol{Q}_{\mathrm{s}}\left(\mathbf{t} \cdot \mathbf{h}^{-1}\right)$ & $\boldsymbol{Q}_{\mathrm{a}} / \boldsymbol{Q}_{\mathrm{s}}\left(\mathbf{m}^{\mathbf{3}} \cdot \mathbf{t}^{-\mathbf{1}}\right)$ & $\boldsymbol{T}_{\mathrm{s}}(\mathbf{K})$ & $\boldsymbol{T}_{\mathrm{a}}(\mathbf{K})$ \\
\hline \hline 1.5 & 1006 & 446 & 898 \\
\hline 3.0 & 1100 & 447 & 896 \\
\hline 4.5 & 1103 & 447 & 901 \\
\hline 6.0 & 1141 & 448 & 897 \\
\hline
\end{tabular}

Table 4. Values of $Q_{\mathrm{a}} / Q_{\mathrm{s}}, T_{\mathrm{s}}$, and $T_{\mathrm{a}}$ at $H=0.8 \mathrm{~m}$.

\begin{tabular}{|c|c|c|c|}
\hline $\boldsymbol{Q}_{\mathbf{s}}\left(\mathbf{t} \cdot \mathbf{h}^{-1}\right)$ & $\boldsymbol{Q}_{\mathrm{a}} / \boldsymbol{Q}_{\mathbf{s}}\left(\mathbf{m}^{3} \cdot \mathbf{t}^{-1}\right)$ & $\boldsymbol{T}_{\mathbf{s}}(\mathbf{K})$ & $\boldsymbol{T}_{\mathbf{a}}(\mathbf{K})$ \\
\hline \hline 1.5 & 881 & 446 & 924 \\
\hline 3.0 & 943 & 447 & 922 \\
\hline 4.5 & 995 & 445 & 921 \\
\hline 6.0 & 1021 & 446 & 923 \\
\hline
\end{tabular}

Table 5. Values of $Q_{\mathrm{a}} / Q_{\mathrm{s}}, T_{\mathrm{s}}$, and $T_{\mathrm{a}}$ at $H=1.0 \mathrm{~m}$.

\begin{tabular}{|c|c|c|c|}
\hline $\boldsymbol{Q}_{\mathbf{s}}\left(\mathbf{t}^{-\mathbf{h}^{-1}}\right)$ & $\boldsymbol{Q}_{\mathrm{a}} / \boldsymbol{Q}_{\mathbf{s}}\left(\mathbf{m}^{3} \cdot \mathbf{t}^{-1}\right)$ & $\boldsymbol{T}_{\mathrm{s}}(\mathbf{K})$ & $\boldsymbol{T}_{\mathbf{a}}(\mathbf{K})$ \\
\hline \hline 1.5 & 791 & 448 & 951 \\
\hline 3.0 & 840 & 446 & 944 \\
\hline 4.5 & 890 & 447 & 946 \\
\hline 6.0 & 910 & 445 & 951 \\
\hline
\end{tabular}

Table 6. Values of $Q_{\mathrm{a}} / Q_{\mathrm{s}}, T_{\mathrm{s}}$, and $T_{\mathrm{a}}$ at $H=1.2 \mathrm{~m}$.

\begin{tabular}{|c|c|c|c|}
\hline $\boldsymbol{Q}_{\mathbf{s}}\left(\mathbf{t} \cdot \mathbf{h}^{-1}\right)$ & $\boldsymbol{Q}_{\mathrm{a}} / \boldsymbol{Q}_{\mathbf{s}}\left(\mathbf{m}^{\mathbf{3}} \cdot \mathbf{t}^{-\mathbf{1}}\right)$ & $\boldsymbol{T}_{\mathbf{s}}(\mathbf{K})$ & $\boldsymbol{T}_{\mathrm{a}}(\mathbf{K})$ \\
\hline \hline 1.5 & 756 & 449 & 959 \\
\hline 3.0 & 790 & 445 & 952 \\
\hline 4.5 & 860 & 447 & 956 \\
\hline 6.0 & 880 & 448 & 959 \\
\hline
\end{tabular}

The heat recovery efficiencies at different slag layer heights are presented in Fig. (8). Heat recovery efficiency is relevant to both air flow rate and air outlet temperature. It is shown under given slag cooling capacity and air feed ratio, heat recovery efficiency first increases and then decreases, and its maximum heat recovery efficiency appears at slag layer height of $1.0 \mathrm{~m}$. The reason is that with the increasing slag layer height under certain slag cooling capacity and air feed ratio, the outlet temperature of blast furnace slag increases but the outlet temperature of circulating air first increases and then decreases.

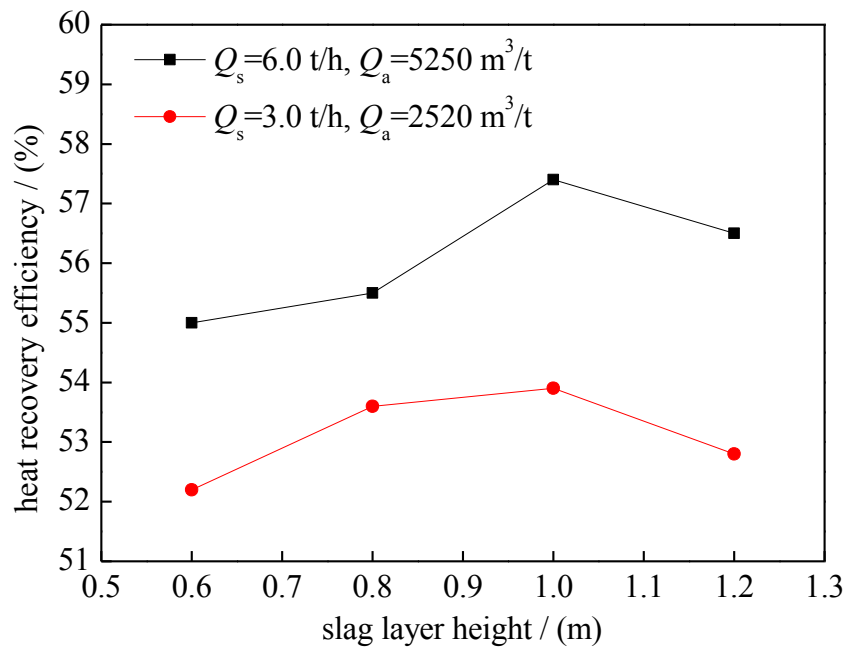

Fig. (8). Values of $\eta$ at different $H$ under different $Q_{\mathrm{s}}$ and $Q_{\mathrm{a}}$.

\section{CONCLUSION}

1) In this work, an experimental apparatus for examining the flight dynamics of blast furnace slag was built. It is shown that the flight distance becomes farther as the rotation speed and/or rotary cup diameter increases. Slag escape velocity is smaller than linear velocity of the outer edge of rotary cup. And the relative velocity difference gets bigger with 
increasing rotation speed while gets smaller with increasing rotary cup diameter.

2) Sensible heat recovery of blast furnace slag was studied in a moving bed apparatus. For a given slag cooling capacity, air feed ratio reduces as slag layer height increases, which needs less circulating air. The outlet temperature of circulating air increases and the heat recovery efficiency first increases and then decreases.

\section{CONFLICT OF INTEREST}

The authors confirm that this article content has no conflict of interest.

\section{ACKNOWLEDGEMENTS}

The project was supported by the Major Science and Technology Program for Water Pollution Control and Treatment (2012ZX07202-001-003).

\section{REFERENCES}

[1] Shen, H.T.; Forssberg, E. An overview of recovery of metals from slags. Waste Manag., 2003 23, 933-949.

[2] Liu, J.X.; Yu, Q.B.; Li, P.; Du, W.Y. Cold experiments on ligament formation for blast furnace slag granulation. Appl. Thermal Eng., 2012, 40, 351-357.

[3] Sun, W.Q.; Cai, J.J.; Du, T.; Zhang, D.W. Specific energy consumption analysis model and its application in typical steel manufacturing process. J. Iron Steel Res. Int., 2010, 17, 33-37.
[4] Sun, W.Q.; Cai, J.J.; Du, T.; Ye, Z. Advances in energy conservation of China steel industry. Sci. World J., 2013, 2013, Article ID 247035, 8 pages.

[5] Xiao, S.; Wu, S.Y.; Zheng, D.S. Slag-washing water of blast furnace power station with supercritical organic rankine cycle. $J$. Cent. South Univ., 2013, 20, 737-741.

[6] Mizuochi, T.; Akiyama, T. "Cold experiments of rotary vaneddisks and wheels for slag atomization. ISIJ Int., 2003, 43, 14691471.

[7] Mizuochi, T.; Akiyama, T.; Shimada, T.; Kasai, E.; Yagi, J. Feasibility of rotary cup atomizer for slag granulation. ISIJ Int., 2001, 41, 1423-1428.

[8] Featherstone, W.B.; Holliday, K.A. Slag treatment improvement by dry granulation. Iron Steel Eng., 1998, 75, 42-46.

[9] Purwanto, H.; Mizuochi, T.; Akiyama, T.; Prediction of granulated slag properties produced from spinning disk atomizer by mathematically model. Mater. Trans., 2005, 46, 1324-1330.

[10] Purwanto, H.; Mizuochi, T.; Tobo, H.; Takagi, M.; Akiyama, T. Characteristics of glass beads from molten slag produced by rotary cup atomizer. Mater. Trans., 2004, 45, 3286-3290.

[11] Seqqiani, M.; Vitolo, S.; Recovery of silica gel from blast furnace slags. Res. Conserv. Rec., 2003, 40, 71-80.

[12] Motz, H.; Geiseler, J.; Products of steel slags an opportunity to save natural resources. Waste Manag., 2001, 21, 285-293.

[13] Oner, M.; A study of intergrinding and separate grinding of blast furnace slag cement. Cement Concrete Res., 2000, 30, 473-48.

[14] Steeghs, A.G.S.; Reuter, M.A.; Heerema, R.H.; Flow of molten slag and iron at $1500{ }^{\circ} \mathrm{C}$ to $1600{ }^{\circ} \mathrm{C}$ through packed coke beds. Metal. Mate. Trans. B, 2005, 36, 765-776.

[15] Zhang, H.; Wang, H.; Zhu, X.; Qiu, Y.J.; Li, K.; Chen, R.; Liao, Q. A review of waste heat recovery technologies towards molten slag in steel industry, Appl. Energy, 2013, 112, 956-966.

[16] Luo, S.Y.; Zhou, Y.M. ; Yi, C.J.; Hydrogen-rich gas production from biomass catalytic gasification using hot blast furnace slag as heat carrier and catalyst in moving-bed reactor. Int. J. Hydrogen Energy, 2012, 37, 15081-15085.

[17] Zhou, Y.M.; Li, C.; Xu, L.L; Luo, S.Y. Yi, C.J. The experimental study of molten blast slag dry granulation. Adv. Mater. Res., 2012, $356,1882-1885$

This is an open access article licensed under the terms of the Creative Commons Attribution Non-Commercial License (http://creativecommons.org/licenses/ by-nc/4.0/) which permits unrestricted, non-commercial use, distribution and reproduction in any medium, provided the work is properly cited. 